\title{
La despolitización mediática de la subjetividad mapuche
}

The media depoliticization of the mapuche subjectivity

Juan Pablo Silva-Escobar

Centro de Investigaciones en Artes y Humanidades,

Facultad de Artes, Universidad Mayor, Chile

jp.silva.escobar@gmail.com

Valentina Raurich

Investigadora Independiente, Chile

vraurichv@gmail.com

\section{Resumen}

El presente trabajo analiza las representaciones que el noticiario de TVN hizo circular respecto de la huelga de hambre mapuche del año 2010. Sostenemos que el modo en que esta protesta fue cubierta ilustra de modo elocuente la forma en que los medios de comunicación masivos han contribuido, tanto en la despolitización de la subjetividad mapuche, como en una deslegitimación de sus demandas políticas. Esto se manifiesta a través del uso de estrategias de visibilización/invisibilización de las luchas por el reconocimiento etno-nacional emprendidas por el movimiento mapuche y que se materializan bajo las estrategias conocidas como "cerco informativo" y "ocultar mostrando". De esta manera, se desplazan unas demandas propiamente políticas al plano biológico y sentimental del espectáculo televisivo.

Palabras clave: Noticiarios de televisión; movimiento mapuche; ideología; neoliberalismo; cerca informativo.

\section{Abstract}

This paper analyzes the representations that TVN's newsreel circulated regarding the mapuche hunger strike of the year 2010. We believe that the manner in which this protest was covered eloquently illustrates the way in which the mass media has contributed, both to the depoliticization of the mapuche subjectivity and to the delegitimization of their political demands. This is evident through the use of strategies of visibilization/invisibilization of the struggles for an ethno-national recognition undertaken by the mapuche movement and they materialize under the strategies known as "informative siege" and "hide showing". In this way, strictly 
political demands are move to the biological and emotional level of the television show.

Keywords: Television news; mapuche movement; ideology; neoliberalism, informative siege

\section{Introducción}

Este trabajo tiene el propósito de analizar las representaciones que el noticiario 24 Horas Central de Televisión Nacional de Chile (en adelante TVN) realizó acerca de la huelga de hambre mapuche del año 2010.1 Nos parece que la representación televisiva de esta manifestación ilustra de modo elocuente la forma en que los medios de comunicación masivos han contribuido, tanto en la despolitización de la subjetividad mapuche, como en una deslegitimación de sus demandas sociales y políticas. Entendemos que la despolitización del conflicto chileno-mapuche opera dentro de una estructura ideológica mayor, de larga data, y que "tiene que ver con el peso de una ideología racial de la soberanía fundada en una metafísica del mestizaje. En ella el reducto mapuche opera como un resto flotando al centro o en los márgenes de una homogeneidad mestiza" (Menard, 2011: 330). De ahí que podamos identificar a través de las representaciones televisivas de la huelga de hambre la producción de una opinión pública que reduce las luchas indígenas a una cuestión vinculada con el terrorismo, la delincuencia y la biopolítica como espectáculo televisivo.

Las diversas movilizaciones y reivindicaciones promovidas desde organizaciones mapuches buscan llamar la atención no sólo de los medios de comunicación de masas, sino también del mundo político, las organizaciones sociales y la sociedad civil, y se inscriben dentro de lo que Axel Honneth (1997) llamó "lucha por el reconocimiento". De acuerdo con Rolf Foerster y Jorge Vergara (2000), esta lucha por el reconocimiento ha incorporado a las ya históricas demandas indígenas la campesina (demandas por créditos agrícolas, mejoramiento de infraestructura, etc.) y la étnica (demandas por el respeto a la identidad mapuche, educación intercultural bilingüe y discriminación legal positiva, entre otras)- una tercera vertiente que incorpora lo campesino y lo étnico pero promoviendo la idea de una

\footnotetext{
1 La elección del Noticiario 24 Horas Central de TVN se debe a que se trata de una empresa ligada al Estado y regulada por una legislación que destaca que el pluralismo y la objetividad deberán manifestarse en toda su programación y, muy especialmente, en los noticieros. Es un canal que se considera público a pesar de que su financiamiento opera bajo la lógica de la autofinanciación.
} 
nación-mapuche, que Foerster y Vergara (2000; 2002) denominan como etnonacional.

Desde la recuperación de la democracia el Estado chileno se ha preocupado por establecer políticas públicas tendientes al reconocimiento de los pueblos originarios, principalmente en aquellas áreas ligadas a la sobrevivencia económica y el fortalecimiento de políticas destinadas a valorizar la diversidad cultural. En tal sentido, el Estado ha centrado su actuar en las dimensiones de tipo campesina y étnica; "mientras la demanda etnonacional no ha encontrado eco en ningún sector político o social significativo de la sociedad chilena" (Foerster y Vergara, 2000: 12). A partir de la negación, por parte del Estado chileno, de parlamentar y negociar respecto de la posibilidad de mayor autonomía y autodeterminación del pueblo mapuche, se ha ido polarizando un conflicto que sitúa en un extremo "al movimiento etnonacional mapuche, que cuestiona de manera radical la política estatal y pugna por una autonomía político-territorial (Foerster y Vergara, 2000: 13). En tanto, en el otro extremo aparecen "los sectores conservadores, donde se incluyen tanto la derecha política como el empresariado y los medios de comunicación" (Foerster y Vergara, 2000: 13).

Javier Lavanchy (1999) plantea que el conflicto chileno-mapuche, tal como lo conocemos hoy en día, tiene como fecha de inicio el año 1997. Fue entonces cuando se dio inicio a la construcción de la represa hidroeléctrica de Ralco, provocando la consecuente oposición de comunidades pewenche. El conflicto no sólo tuvo una inusual resonancia en los medios, sino que puso en el debate público la pugna entre un sector del mundo pewenche -que encontró una red de apoyo entre ecologistas e indigenistas-, y la transnacional española Endesa -que fue apoyada por el gobierno de Eduardo Frei. Este antagonismo, que se representaba mediáticamente como un problema puntual entre particulares, paulatinamente adquirió resonancia política y simbólica dentro del mundo mapuche y sectores afines de la sociedad civil. Ralco se configuró en el imaginario mapuche como un conflicto que afectaba a todo el pueblo mapuche y lo enfrentaba al Estado chileno y sus políticas neoliberales. Otro hecho significativo ocurrido a finales de 1997 y, tal vez, más relevante que Ralco, fue la primera quema de camiones madereros de la Forestal Bosque Arauco, que de acuerdo con José Mariman (1998), "generaron un nuevo escenario para la confrontación por restitución de tierras expoliadas a la nación mapuche". A partir de estos hechos y a lo largo de casi dos décadas de construcción mediática de la movilización indígena, se ha "popularizado la representación de un "conflicto mapuche' en el que las demandas políticas han sido obliteradas como si se tratase de problemas de seguridad pública suscitados entre activistas y propietarios agrícolas" (Muñoz Román, 2010: 30). 
Dentro de este contexto los medios de comunicación hegemónicos se han empeñado en construir representaciones donde la "cuestión indígena" es inscrita dentro de la ideología dominante que hace de la nación un todo inseparable (Foerster, 2002). Analizar el modo en que esa ideología se positiva en las representaciones mediáticas de la huelga de hambre, debe tener en cuenta el hecho de que "las representaciones y valoraciones que se producen en los medios de comunicación deben entenderse en la perspectiva de una lucha política por el significado" (Muñoz Román, 2010: 31). De ahí que se pueda argumentar que los medios de comunicación hegemónicos contribuyen en la invisibilización de la lucha política por el reconocimiento étnico-nacional mapuche, e instalan una suerte de soberanía mestiza que opera bajo "el supuesto de que los 'pueblos originarios' habrían desaparecido bajo una mezcla homogeneizada" (Muñoz Román, 2010: 36).

Partimos de la idea de que la televisión, y específicamente el noticiario televisivo, se configura como un dispositivo visual de cultura y poder, legitimado socialmente para hacer circular representaciones de los acontecimientos de interés general, y "cumpliendo una función de 'bisagra relacional' entre el Estado y el ciudadano" (Antezana, 2015: 187). Entendemos que las representaciones televisivas son discursos que se articulan en modelos de pensamiento y en mecanismos de dominación propios de una época y un momento histórico determinado (Foucault, 1995). De igual manera, somos conscientes que los medios de comunicación son parte integrante de la realidad social y que esa integración, principalmente, se da a través de la producción de los llamados "efectos de realidad" mediante los cuales se fabrica una visión mediática que contribuye a crear la realidad que pretende describir (Champagne, 2010; Barthes, 1972). Por lo tanto, si los movimientos sociales requieren llamar la atención de los medios de comunicación se debe al hecho de que "los malestares sociales sólo tienen existencia visible cuando los medios hablan de ellos" (Champagne, 2010: 51). Esto nos conduce hacia una cuestión más profunda y que tiene directa relación con el hecho de que la estructura social del capitalismo neoliberal se encuentra construida alrededor de (pero no determinada por) los medios de comunicación (Castells, 2010).

En términos metodológicos las noticias referidas a la huelga de hambre serán trabajadas desde lo que Roland Barthes (2001) denominó "lexias" o unidades de lectura. La lexia comprenderá algunas veces unos pocos planos, o unas cuantas secuencias, o algunas escenas, dependerá de cuál sea el mejor espacio posible para observar los sentidos, las connotaciones, las ideologías. Es decir, trabajaremos con un texto audiovisual quebrado, en donde "al señalar el significado de cada lexia, no se pretende establecer la verdad del texto (su estructura profunda estratégica), sino su plural (aunque éste sea parsimonioso)" (Barthes 2001: 10). A través de la búsqueda del plural de las noticias referidas a la huelga de hambre pretendemos 
realizar un desplazamiento del significado al significante, del enunciado a la enunciación.

Sostenemos que los significados adheridos a la representación de la protesta social no pueden significar por sí mismos, hay que hacerlos significar y volverlos legibles, y es en ese proceso de inteligibilidad cuando el punto de vista de los noticiarios de televisión respecto del conflicto chileno-mapuche se vuelve favorable o mejor dicho contribuye a diseminar la ideología de la "soberanía mestiza". Ideología que está codificada en los mensajes y que contribuye tanto a la despolitización de la subjetividad mapuche como a la deslegitimación de las movilizaciones indígenas. De esta manera, se desplazan unas demandas propiamente políticas al plano biológico y sentimental del espectáculo televisivo.

\section{Espiral del silencio}

Los medios de comunicación de masas distribuyen numerosas representaciones de la realidad social. Esas representaciones no sólo contribuyen en la amplificación de determinados discursos, sino también establecen lo que algunos especialistas (McCombs, 2006; Rodriguez, 2004; McQuail, 2000, 1981; Price, 1994) han conceptualizado como Agenda-setting, entendida ésta como la influencia que ejercen los mass media sobre las audiencias a través de la circulación de determinados temas que son catalogados como relevantes y que son transferidos a la opinión pública. La agenda-setting puede explicarse y sintetizarse con la frase acuñada por Bernard Cohen, quien planteaba que "la prensa no tiene mucho éxito en decir a la gente qué tiene que pensar pero sí lo tiene en decir a sus lectores sobre qué tienen que pensar" (1963: 13). Por lo tanto, la idea de agenda se utiliza para dar cuenta del modo en que los temas seleccionados por los medios pasan a ser subrayados e incorporados dentro del debate público.

Como han sostenido varios estudiosos (McCombs, 2006; McQuail, 2000; 1981; Briggs y Burke, 2002; Martín-Barbero, 1999; Mattelart, 2002; Orozco, 2000; Wolton, 1995; Wolf, 1994; 1996), el proceso de confección y fijación de la agenda constituye una manera de elaborar un marco de referencia para comprender el mundo social. Al fijar la agenda, los medios de comunicación no sólo son capaces de difundir impresiones y dirigir selectivamente la mirada hacia problemáticas específicas que son instaladas como prioridades para su conocimiento y eventual debate, sino también proporcionan un marco conceptual que guía los énfasis y perspectivas que se les deben dar a los acontecimientos relatados.

Ahora bien, cuando un medio de comunicación establece una determinada agenda, ese acto comunicativo implica una selección y, por lo tanto, la negación de otros acontecimientos. Desde nuestro punto de vista, la instalación de la agendasetting referida a los movimientos sociales puede ser analizada desde dos puntos. 
Primero a partir de aquello que se muestra o proyecta en las pantallas de nuestros televisores. En el caso específico de la huelga de hambre, aquello que se exhibe puede calificarse, siguiendo a Pierre Bourdieu (1997), como "ocultar mostrando". Es decir, se trata de representaciones en las que se lleva a cabo un proceso tal de manipulación de la información, que se termina mostrando algo completamente distinto que no se condice con la realidad objetiva, o en el mejor de los casos, se presenta de tal forma de que pasa inadvertido. Por otro lado, la agenda-setting también puede ser analizada a partir de aquello que los medios deliberadamente deciden silenciar y no incorporar en el debate público. Esta estrategia se denomina "cerco informativo", entendido éste como la clausura narrativa, el aislamiento discursivo, la incomunicación ideológica y económica ejercida por la hegemonía en términos mediáticos (Sel, 2009).

Un ejemplo claro de "cerco informativo" es el que experimentaron los 34 presos mapuches que el día 12 de julio de 2010 iniciaron una huelga de hambre indefinida que los mantuvo en ayuno por 82 días. Esta protesta tenía como objetivo visibilizar la injusticia que significaba estar siendo acusados de infringir la ley antiterrorista. Durante los primeros 38 días de huelga los noticiarios de televisión no informaron acerca de estos hechos. Organizaciones sociales y dirigentes indígenas denunciaron esta situación. Así por ejemplo, Antonio Cadín, Werken de la comunidad Mapuche Juan Paillalef, de las cercanías de la ciudad de Temuco, señalaba en entrevista con el portal Digital "Kaos en la Red", la necesidad de "romper el cerco comunicacional porque en Chile todo se silencia".2 Desde una perspectiva similar, la Coordinación de Organizaciones Autónomas Mapuche, a través de su vocero Manuel Chocori, señaló "que este Gobierno ha montado un cerco de comunicación con el objeto de silenciar las movilizaciones emprendidas por los hermanos recluidos en las cárceles en territorio mapuche, lo que continúa con la política de deslegitimación que han pretendido imponer en la opinión pública por medios televisivos". ${ }^{3}$

Por su parte, el editor del portal digital "MapuExpress", Sergio Millamán, y Luis Cuello, autor del portal digital "Otra Prensa", presentaron una denuncia ante el Consejo Nacional de Televisión por el silencio informativo sobre la huelga de hambre mapuche. En su denuncia, Millamán y Cuello acusaron a los canales de televisión de libre recepción de infringir el artículo $1^{\circ}$, inciso final de la ley 18.838, en lo concerniente al deber de respetar el pluralismo y la democracia. Según Luis Cuello, el objetivo de esta denuncia "es visibilizar un comportamiento sistemático de la televisión, que niega realidades, actores sociales, conflictos y particularmente lo que ellos mismo han llamado 'conflicto mapuche'”. ${ }^{4}$ En su acusación señala que los

\footnotetext{
2 Antonio Cadín entrevistado por Rossana Cárcamo (citado en Silva-Escobar, 2013, p. 163).

3 Manuel Chocori citado en Silva-Escobar, 2013, p. 163.

${ }_{4}^{4}$ Luis Cuello citado en Silva-Escobar, 2013, p. 164).
} 
canales de televisión, al no informar sobre los hechos vinculados a la huelga de hambre mapuche y, principalmente, al no informar adecuadamente acerca "de las demandas que reivindican los huelguistas, contribuyen a consolidar una visión sesgada de la sociedad hacia el pueblo mapuche, que finalmente se traduce en el fortalecimiento de prejuicio y una visión discriminatoria hacia el pueblo mapuche".5

A partir de las lecturas críticas que realizan los dirigentes mapuches, ya sea por la ausencia de noticias referidas a la huelga de hambre mapuche del año 2010 "cerco informativo"-, o bien al modo en que el noticiario televisivo construye las manifestaciones sociales -"el ocultar mostrando"-, los movimientos sociales no sólo subrayan la "incorrecta" forma en que son representados audiovisualmente sino que, al designar sus causas y responsables, también asumen una función normativa. Al señalar lo que está bien y lo que está mal, se traza una frontera entre el "nosotros" y el "ellos", lo que trae aparejado un componente de identificación e identidad compartida entre quienes poseen una visión común. Por lo tanto, al realizar una lectura resistente a los textos noticiosos, los movimientos sociales se configuran como una audiencia que cuestiona no sólo el particular modo que tiene la televisión de construir sus movilizaciones, sino también realizan una crítica a la hegemonía mediática-discursiva a la que se ven sometidos. Por otra parte, la preocupación que muestran los movimientos sociales y sus dirigentes por la cobertura periodística de sus acciones, corrobora la idea de que gran parte de las reivindicaciones, así como el reconocimiento que buscan alcanzar dentro del campo social se juega a través de la lucha por la visibilidad mediática.

Ahora bien, tanto "el cerco informativo" como "el ocultar mostrando" se vinculan con un aspecto cultural mayor y que tiene directa relación con lo que Elizabeth Noelle-Neumann (1995) ha denominado espiral del silencio. Este concepto, surgido de la teoría sobre la opinión pública, postula que para evitar el aislamiento en los asuntos públicos importantes, mucha gente se guía por las opiniones que se instalan y perciben como dominantes dentro del campo social. Es decir, los sujetos al estar inmersos dentro de determinados contextos históricos, políticos y culturales, se dejan influenciar por aquellas opiniones que perciben como socialmente mayoritarias y, por lo general, tienden a disimular sus opiniones cuando perciben que están en minoría (Noelle-Neumann, 1995; McQuail, 2000). En este sentido, tanto "el cerco informativo" como "el ocultar mostrando" que se impuso mediáticamente sobre la huelga de hambre mapuche entran en una espiral del silencio, en la medida en que la televisión contribuyó en la instalación de opiniones y discursos dominantes que se van sedimentando como sentido común y que se imponen sobre otras opiniones y discursos.

5 Texto recogido del portal digital Otra Prensa, disponible en: http://www.otraprensa.com/wpcontent/uploads/2011/04/denuncia-huelga-mapuche-2011.pdf 
Al cuestionar estos mecanismos de silenciamiento e invisibilidad, lo que los movimientos sociales intentan hacer es llamar la atención sobre la forma en que las relaciones sociales, culturales y políticas se reproducen y legitiman con el consentimiento más o menos voluntario de los dominados. Se trata, por lo tanto, de una crítica que apunta de lleno, no sólo a la hegemonía discursiva de la televisión, sino también al modo en que el poder mediático se articula como un instrumento gregario que suministra una serie de valores "que aparecen en los distintos grupos y clases sociales, en función de sus condiciones y relaciones históricas, mediante los cuales 'negocian' y responden a las condiciones de existencia" (Hall, citado en McQuail, 2000: 166).

\section{La huelga de hambre en el noticiario}

Un grupo de 34 presos mapuches recluidos en distintas cárceles del sur del país llevaban 38 días en huelga de hambre y el noticiario 24 Horas Central de TVN no había entregado información alguna sobre el tema. Luego de promocionar la próxima teleserie a estrenar por el canal e ir a publicidad, la conductora introduce el tema por primera vez en el noticiario del día 18 de agosto de 2010. Esta primera nota se concentró en mostrar imágenes de carabineros tomando detenidos a manifestantes mientras el periodista narraba: "Con violentos incidentes terminó una marcha de apoyo a los presos mapuches que hoy día cumplieron 38 días en huelga de hambre".6 Se presentaron cuñas de los voceros mapuches, quienes hablan del estado de salud de los huelguistas. Inmediatamente después se muestra al director regional de gendarmería, quien habla sobre las medidas cautelares que se están tomando para suministrarles comida a la fuerza a los huelguistas.

Para alguien que sólo se informa a través de la televisión, como es el caso de la mayoría de los chilenos (CNTV, 2008)7, esta primera nota sobre la huelga de hambre mapuche no revelaba nada acerca de las causas que habían motivado la acción. Nada se explica, por ejemplo, acerca de las acusaciones en contra de los comuneros, quiénes son los huelguistas, de qué se trata el llamado "conflicto mapuche". Sólo al final de la nota se menciona que una de las luchas que llevan a cabo los mapuches procesados por la ley antiterrorista es conseguir su derogación; pero nada se dice del por qué los están procesando bajo esa ley, ni mucho menos cuáles son sus consecuencias.

\footnotetext{
6 Voz en off de la periodista Nadia Arias, realizadora de la nota 24 Horas Central de TVN del día 18 de agosto de 2010

7 La Sexta Encuesta Nacional de Televisión de 2008 revela que los noticiarios de televisión son la principal fuente de información de los chilenos $(81,8 \%)$ y que la mayoría los ve todos los días $(74,7 \%)$.
} 
Durante el mes de agosto, en total se realizaron cuatro notas acerca de la huelga de hambre. Si bien se entregaron algunos antecedentes marginales acerca de los motivos de la movilización, por lo general estas notas se concentraron en resaltar el estado de salud de los huelguistas y fijar la atención sobre aquellos personeros de la élite eclesiástica y política que pudieran incidir en una solución. En menor medida aparecen en pantalla los voceros mapuches expresando su opinión acerca de la salud de los manifestantes.

Durante el mes de septiembre la huelga de hambre se tomó la parrilla informativa de TVN y se presentaron 29 notas que comenzaron a fijar en la esfera pública una visión acerca de la demanda y su resolución. Estas notas enfocaban el tema desde tres ángulos: 1) el rol central que debe jugar la clase política y la elite chilena en la búsqueda de soluciones para el conflicto; 2) describir, a partir de una mirada despolitizada, el movimiento y las demandas de los propios manifestantes; y 3) poner énfasis en las medidas necesarias para salvaguardar las vidas de los manifestantes.

Así, por ejemplo, la nota del 3 de septiembre de 2010 se concentró en informar sobre la reunión que sostuvieron los políticos del gobierno y la oposición para solucionar la huelga de hambre. La conductora introdujo la nota señalando: "De vuelta aquí en el país, 54 días cumple la huelga de hambre y la situación de los comuneros mapuches se complica. El presidente Piñera aseguró que, de la misma forma que su gobierno trabaja en el rescate de los mineros, procederá en este caso para no lamentar una desgracia". 8

En esta nota se manifiesta la posición mediática del gobierno con respecto a la huelga de hambre y que el canal asume sin acotaciones, convirtiéndose de ese modo en el principal divulgador de esas posturas. Así, TVN construye un relato que asume que el conflicto debe resolverse casi exclusivamente entre la clase política, una elite que debe llegar a acuerdos y alcanzar así la unidad nacional en vísperas de conmemorar el bicentenario. Al mismo tiempo, la nota trata de equiparar la huelga de hambre mapuche con el rescate de los 33 mineros atrapados en la mina San José, de la región de Atacama; es decir, se lleva a cabo el desplazamiento de un conflicto que es esencialmente político al plano biológico y sentimental de rescatar unas "vidas chilenas en peligro", misión en la que se pone en juego la solidaridad compasiva de toda una nación.

El 11 de septiembre de 2010, el noticiario presentó en exclusiva una entrevista a uno de los huelguistas en la cárcel de Temuco. La nota fue introducida por el conductor, quien resaltó el carácter de exclusividad de la nota y el hecho de

8 Consuelo Saavedra, 24 Horas Central de TVN del día 3 de septiembre de 2010. 
que a partir de ella se podrá “conocer de primera fuente los objetivos, las propuestas y hasta dónde están dispuestos a llegar los huelguistas".9

Periodista: "Mañana del 11 de septiembre en la cárcel de Temuco y la visita de los familiares de los huelguistas concita alto interés. Quisimos verlos e ingresamos al recinto penal justo en el día 62 de esta huelga de hambre iniciada por comuneros mapuches que exigen el término de las causas por la ley antiterrorista. En exclusiva y por primera vez podemos ver a quienes están imputados por los hechos de violencia registrados en la Araucanía, quienes designaron a Mauricio Huaiquilao Huaiquilao de 33 años, imputado por atentados incendiarios y que la Fiscalía señala como uno de los que habría recibido instrucción paramilitar en las FARC colombianas. Fueron algunos segundos en los que pudo hablar con 24 Horas, lo suficiente para saber qué piensan del proyecto presentado por el Gobierno sobre modificar la ley que sanciona las conductas terroristas". 10

Mauricio Huaiquilao (preso mapuche en huelga de hambre): "No hay ninguna solución para nosotros. Por un lado están planteando imponiendo una reforma a la ley que no se nos consulta, analizando bien, en detalle qué significa eso. No resuelve nada en el fondo y lo que estamos planteando son temas políticos concretos que el gobierno no quiere abordar. Por un tema de orgullo, por un tema de presión de la derecha económica, no quieren sentarse con nosotros a conversar que es un tema, que es algo tan simple que estamos planteando".

Periodista: "Saben que su salud se ha ido deteriorando, de hecho, los 34 han bajado de peso de manera sostenida en los penales de Temuco, Cholchol, Angol y Concepción. Pese a ello su vocero dice estar firme y descartan entregar gestos al Gobierno que interfieran en el ayuno".

Mauricio Huaiquilao (preso mapuche en huelga de hambre): "Con este es un movimiento de protesta que no queremos terminar por una razón bien sencilla. Primero que nada queremos demostrarle al Gobierno que nosotros somos capaces políticamente y organizativamente de plantearnos por nuestros principios, y que se consideren no solamente las demandas específicas de la huelga, queremos que se considere el

9 24 horas Central de TVN del día 11 de septiembre de 2010 .

10 Voz en off del periodista Fernando Rey. 24 Horas Central de TVN del día 11 de septiembre de 2010. 
trasfondo político que tiene todo esto: los conceptos que nosotros planteamos de resistencia, de reconstrucción, de liberación de nuestro pueblo".

Periodista: "Dicen estar unidos y asumen su condición de líderes de un pueblo mapuche que ha luchado por años en la zona sur por la tenencia de la tierra".

Mauricio Huaiquilao (preso mapuche en huelga de hambre): " $L a$ fórmula que nosotros estamos planteando en este momento es bien simple, que el gobierno se siente a conversar. Tenemos una mesa de diálogo elaborada, con la gente dispuesta a ir a conversar. Falta solamente la voluntad del gobierno de decir, tal día, tal fecha, nos sentamos a conversar. $Y$ si aquí tiene que haber un costo político, que significa la pérdida de la vida de un hermano mapuche, hay un consenso interno de llegar hasta ese límite. Límite lamentable pero que nosotros asumimos con mucha dignidad, sabiendo y entendiendo de que son cosas importantes no para nosotros. Nosotros también planteamos modificar la ley antiterrorista".

Periodista: "Registro único que muestra a los comuneros mapuches que sostienen por más de dos meses una huelga de hambre que ha puesto el tema en el centro del análisis nacional".

Las palabras de Huaiquilao evidencian que, para sus protagonistas, la huelga de hambre se inscribe como una práctica política, como un dispositivo radical para devolver el conflicto chileno-mapuche a un plano político, es decir, a un plano en el que se recupere la histórica necesidad de deliberar, negociar y pactar en torno a la diferencia por la que los sujetos se reconocen como legítimos adversarios. Sin embargo, inmediatamente a continuación el noticiario presentó una nota en la cual el tema central vuelve a ser el rescate de las vidas en peligro de muerte. El conductor introdujo la nota diciendo: "Efectivamente, cuando se cumplen 62 días de la huelga de hambre, la preocupación por su estado de salud aumenta mientras el trabajo legislativo para revisar la ley antiterrorista continuó extraordinariamente en esta jornada".11 Así, el noticiario vuelve a reintroducir las demandas mapuches dentro de su cariz biológico-jurídico, despolitizando aquello que había sido politizado en la nota anterior. En los días siguientes esto se consolidó aún más a través de numerosas notas en las que el tema central fue el traslado de alguno de los

11 Juan José Lavín, conductor 24 horas Central de TVN del día 11 de septiembre de 2010. 
comuneros en huelga de hambre hacia algún recinto hospitalario, o cómo los diversos parlamentarios intentaban llegar a acuerdos para modificar la ley antiterrorista.

Recurriendo a una fórmula tradicional para transmitir una supuesta objetividad periodística, el noticiario narró la protesta social de los mapuches a través de las opiniones vertidas desde la oposición y el gobierno. Esta mirada unidimensional y jerárquica presenta a la elite política y eclesiástica como la encargada de solucionar la problemática, al mismo tiempo que refleja la postura gubernamental que tiende a despolitizar el conflicto y negar la capacidad de los propios involucrados de llevar a cabo sus propias negociaciones.

En las pantallas de nuestros televisores se construyeron relatos en los cuales la demanda política del movimiento mapuche es reemplazada por una doble mirada mediática y gubernamental, por un lado la televisión pone el acento en la dimensión sentimental de salvaguardar la vida de los huelguistas a como dé lugar y en el espectáculo televisivo que ello implica, mientras que el gobierno responde a las demandas indígenas con medidas jurídico-militares por las que el adversario político deviene criminal o terrorista (Foerster y Montecino, 2007). Se trata, por tanto, de borrar el imaginario político mapuche que hay detrás de la movilización, lo que resulta aún más evidente al constatar que ninguna de las notas referidas a la huelga de hambre hizo mención a la problemática de la tierra, que es uno de los elementos centrales del conflicto. El problema de la "tierra mapuche" como señalan Foerster y Montecino, conlleva "una centralidad compleja, entre otras cosas, por no poder desprenderse ni de los vínculos políticos con el Estado (sistema reduccional-títulos de merced, exención de impuestos, registro de tierras en la CONADI, autorización para venta, etc.) ni tampoco de la 'comunidad"' (2007: 134).

En suma, el noticiario central de TVN logró fabricar una visión mediática del conflicto que, al centrarse en la inmediatez de salvaguardar la vida, logra construir informaciones sustentadas en la lógica del "ocultar mostrando". Lo que se ocultó fue el hecho de que con la huelga de hambre, los 34 prisioneros mapuche no sólo estaban reivindicando el derecho a condiciones procesales básicas, sino que estaban manifestando la necesidad de que en Chile se considere una nueva forma de tratar los conflictos y las diferencias respecto de la conformación misma de la soberanía y del Estado de derecho. Se trató de una lucha para que estas diferencias y conflictos tengan un verdadero espacio de expresión y de negociación y no caigan automáticamente en el rango extrapolítico, ya sea del terrorismo, o de los derechos humanos mínimos que el Estado o el mercado deben satisfacer unidireccionalmente apelando a la supuesta neutralidad de la eficacia tecnocrática, o a la vaga emotividad de la caridad y el espectáculo compasivo. 


\section{Conclusiones}

Las representaciones que hizo circular el noticiario 24 Horas Central de TVN sobre la huelga de hambre expresan una mirada conservadora respecto de las reivindicaciones etno-nacionales del movimiento mapuche, y distribuye una visibilidad mediática que tiende a la despolitización de la subjetividad mapuche y la deslegitimación de sus demandas. De este modo, el noticiario fabrica un discurso unidireccional, que conduce al borramiento político del movimiento mapuche, ya sea mediante una sobreexposición mediática que apela a la puesta en espectáculo ("el ocultar mostrando"), o a través de una subexposición que recurre a la censura ("el cerco informativo").

Al negar la condición política del movimiento mapuche, el noticiario evidencia una cuestión social y cultural que tiene directa relación con la pugna por el derecho a la imagen, el discurso y la representación en la esfera pública. Como ha observado Georges Didi-Huberman (2014), la imagen mantiene una relación antropológica de muy larga data con las cuestiones relativas al derecho civil, al espacio público y a la representación política. Este derecho a la imagen se ha posicionado, hoy en día, como una cuestión de propiedad privada donde tiene lugar una lucha por hegemonizar el espacio mediático y, con ello, definir quienes tienen derecho a la imagen y quienes no lo tienen. Lo interesante de esta lucha es que deja entrever el modo en que la televisión no impone tanto una ideología dominante, sino más bien contribuye a que ésta se naturalice en virtud de un consenso que no es puesto en tela de juicio, y que tiende a la privatización del derecho a la imagen y el reconocimiento social.

La huelga de hambre mapuche fue un claro ejemplo de cómo operó esta privatización del derecho a la imagen, al discurso y a la representación, e instaló un consenso no cuestionado, donde la demanda política del movimiento mapuche fue inscrita dentro de una mirada mediática y gubernamental, que buscó resaltar la dimensión épico-emotiva de proteger la vida de los huelguistas a como dé lugar, pero al mismo tiempo se sobreexponían las demandas indígenas con miradas y medidas jurídico-militares por las que el adversario político deviene criminal o terrorista. Se trató, por tanto, de borrar de la subjetividad mapuche el componente político que había detrás de la movilización y con ello se les negó su derecho a la imagen y a la palabra.

En síntesis, este borramiento responde a la naturalización de la ideología de la "soberanía mestiza" que, en términos mediático-televisivos, positivó una representación monolítica y subordinada de la diferencia, de modo que la lucha por el reconocimiento etno-nacional fue entendida como un acto de transgresión de la institucionalidad neoliberal. Esta razón comunicacional promovió una discursividad que, en última instancia, evidencia un racismo encubierto, un poder sustentado en el 
estatuto soberano que concibe al país como un todo en el que cohabitarían diversos grupos (etnias) que persiguen la igualdad social, pero que se subordinan a la idea de nación como un todo coherente (Foerster, 2002). Bajo esta figura ideológica, el noticiario de TVN distribuyó un imaginario hegemónico que hace de lo mapuche una categoría genérica, es decir, una categoría desprendida de cualquier subjetividad histórico-política.

Si bien este imaginario reconoce lo mapuche como diversidad cultural ligada, principalmente al patrimonio y la identidad, niega su contingencia histórica y política. La despolitización de la subjetividad mapuche implica la clausura del sujeto mapuche como un actor político que se relaciona con el Estado chileno de manera distinta a como lo puede hacer un pescador, un campesino, un minero. En tal sentido, el noticiario de TVN reproduce una versión de la subjetividad mapuche que es la proyección de lo que las instituciones mediáticas (y el Estado) quieren que sea: un sujeto ahistórico, congelado en el tiempo, naturalizado como expresión idealizada (colonizada) de una inscripción mediática que, al no reconocer las demandas mapuches como reivindicaciones políticas, niega la posibilidad de inscribir la subjetividad mapuche como un adversario político legítimo con el cual deliberar, negociar y pactar.

\section{Bibliografía}

Antezana, L. (2015): "La función política de la televisión e internet en contextos de movilización social: el caso chileno", Chasqui. Revista Latinoamericana de Comunicación, 128, pp.183-196.

Barthes, R. (1972): "El efecto de realidad", en Lo verosímil. Buenos Aires, Editorial Tiempo Contemporáneo, pp. 95-101.

Barthes, R. (2001): S/Z. Buenos Aires, Siglo XXI editores.

Bengoa, J. (1999): Historia de un conflicto. El Estado y los mapuches en el siglo XX. Santiago de Chile, Editorial Planeta.

Bourdieu, P. (1997): Sobre la televisión. Barcelona, Anagrama.

Briggs, A. y Burke, P. (2002): De Gutenberg a internet. Una historia social de los medios de comunicación. Madrid, Taurus.

Castells, M. (2010): Comunicación y poder. Madrid, Alianza Editorial. 
Champagne, P. (2010): "La visión mediática", en P. Bourdieu, coord., La miseria del mundo. Madrid: Akal, pp. 51-63.

Consejo Nacional de Televisión (CNTV) (2008): Sexta encuesta nacional de televisión 2008. Santiago de Chile, Consejo Nacional de Televisión.

Didi-Huberman, G. (2014): Pueblos expuestos, pueblos figurantes. Buenos Aires, Manantial.

Foerster, R. (1999): “¿Movimiento étnico o etnonacional mapuche?”. Revista de Crítica Cultural, no18, pp. 52-58.

Foerster, R. (2002): "Sociedad mapuche y sociedad chilena: La deuda histórica", Polis. Revista Latinoamericana, 1(2), pp. 2-15.

Foerster, R. y S. Montecino (2007): "Un gesto implacable guardado en nuestras entrañas. Notas reflexivas sobre una encuesta iluminadora", Revista de Estudios Públicos, 105, pp. 121- 140.

Foerster, R. y Vergara, J. (2000): "Etnia y nación en la lucha por el reconocimiento. Los mapuches en la sociedad chilena”, Estudios Atacameños, 19, pp. 11-42.

Foerster, R. y Vergara, J. (2002): "Permanencia y Transformación del Conflicto Estado-mapuches en Chile", Revista Austral de Ciencias Sociales, 6, pp. 35-45.

Foucault, M. (1995): Las palabras y las cosas. México D. F., Siglo XXI Editores.

Honneth, A. (1997): La lucha por el reconocimiento. Por una gramática moral de los conflictos sociales. Barcelona, Crítica.

Lavanchy, J. (1999): "Perspectivas para la comprensión del conflicto mapuche". Proyecto de Documentación Ñuke Mapu. Recuperado de: http://www.mapuche.info/mapuint/lava2.html

Lull, J. (1997): Medios, comunicación, cultura. Aproximación global. Buenos Aires, Amorrortu Ediciones.

Mariman, J. (2012): Autodeterminación. Ideas políticas mapuches en el albor del siglo XXI. Santiago de Chile, LOM Ediciones. 
Mariman, J. (1998): "Lumaco y el Movimiento Mapuche", Proyecto de documentación Ñuke Mpau. Recuperado de: http://www.mapuche.info/mapuint/Lumako00.htm

Martín-Barbero, J. (1999): "El miedo a los medios. Política, comunicación y nuevos modos de representación", Nueva Sociedad, 161, pp. 43-56.

Mattelart, A. (2002): Historia de la sociedad de la información. Barcelona, Paidós.

Mccombs, M. (2006): Estableciendo la agenda. El impacto de los medios en la opinión pública y en el conocimiento. Barcelona, Paidós.

Mcquail, D. (2000): Introducción a la teoría de la comunicación de masas. Barcelona: Paidós.

Mcquail, D. (1985): "Influencia y efectos de los medios masivos", en J. Curran, M. Gurevitch y J. Woollacott, Comp., Sociedad y comunicación de masas, México D. F., Fondo de Cultura Económica, pp. 85-111.

Menard, A. (2011): "Archivo y reducto. Sobre la inscripción de lo mapuche en Chile y Argentina”, Revista de Antropología Iberoamericana, 6(3), pp. 315-339.

Noelle-Neumann, E. (1995): La espiral del silencio: opinión pública, nuestra piel social. Barcelona, Paidós.

Muñoz Román, R. (2010): "Discurso informativo y luchas por el reconocimiento el 'conflicto mapuche' en el Mercurio y La segunda (Chile, 2008-2009)", Perspectivas de la comunicación, 3(2), pp. 29-47.

Orozco, G. (2000): Lo viejo y lo nuevo investigar la comunicación en el siglo XXI. Madrid, Ediciones de la Torre.

Price, V. (1994): La opinión pública. Esfera pública y comunicación. Barcelona, Paidós.

Sel, S. (2009): "Comunicación alternativa y políticas públicas en el combate latinoamericano", en S. Sel, comp., La comunicación mediatizada: hegemonías, alternatividades, soberanías, Buenos Aires, CLACSO, pp. 13-36.

Silva-Escobar, J.P. (2013): Discurso, representación y cultura. La valoración simbólica de los noticiarios de televisión: los movimientos sociales chilenos y la visibilidad social. Tesis doctoral inédita, Universidad de Valladolid, España. 
Wolf, M. (1996): La investigación en la comunicación de masas. Barcelona, Paidós.

Wolf, M. (1994): Los efectos sociales de los media. Barcelona, Paidós.

Wolton, D. (1995): Elogio del Gran Público. Una teoría crítica de la televisión. Barcelona, Gedisa.

Fecha de recepción: 9 de abril de 2020

Fecha de aceptación: 24 de mayo de 2020 